\title{
EDICIÓN DEL TRATADO DE PAZ BILINGÜE DE 1405 ENTRE EL REINO DE GRANADA Y LA CORONA DE ARAGÓN
}

\author{
Ana Labarta \\ Universitat de València
}

\begin{abstract}
Resumen: El artículo ofrece la edición completa de las dos partes (árabe y aragonesa) de este documento y la traducción al castellano de la parte árabe, de las que hasta ahora no disponíamos. Era necesario realizarlas y ponerlas al alcance de la comunidad científica para tener una base fiable a partir de la que emprender su estudio diplomático y realizar cualquier otro acercamiento de tipo histórico.

Palabras clave: Nazaríes, Corona de Aragón, Reino de Sicilia, diplomática, paces, siglo XV.

Edition of the Bilingual Peace Treaty of 1405 between the Kingdom of Granada and the Crown of Aragon

Abstract: The article offers the complete edition of the two parties (Aragonese and Arabic) of this document and the translation into Spanish of the Arabic text, which so far we didn't have. It was necessary to carry out this task and put it at the disposal of the scientific community in order to have a reliable basis before undertaking its internal diplomatic study and any historical approach.
\end{abstract}

Key words: Nasrids, Crown of Aragon, Kingdom of Sicily, diplomatics, peace treaty, 15th century.

\section{ANTECEDENTES}

En 1405 se firmó un tratado de paz, libre circulación, libre comercio y ayuda mutua entre el soberano nazarí de Granada Muhammad VII al-Musta'ìn bi-llāh (1370-1408), Martín I el Humano de Aragón (1356-1410) y su hijo Martín I de Sicilia (1374-1409). El Archivo de la Corona de Aragón (ACA) conserva uno de los dos originales bilingües en árabe y aragonés sobre pergamino que se hicieron, así como la copia contemporánea en el registro real de la parte romance.

El tratado ha sido objeto de diversas aproximaciones. Bofarull (1847) publicó la parte en aragonés, basándose en la copia que está en el registro del ACA. Giménez Soler (1908) fue el primero en dar a conocer las dos partes a partir del pergamino. Pero su edición ha quedado anticuada, pues eliminó el texto que le parecía superfluo para sus estudios históricos, presenta erratas, y

Data de recepció: 14 d'octubre de 2018 / Data d'acceptació: 3 de desembre de 2018. 
no ofreció la traducción de la parte árabe. A pesar de ser conocido, no se recogió entre los documentos árabes diplomáticos del Archivo de la Corona de Aragón publicados en el libro de Alarcón y García de Linares (1940), tal vez porque no se encuentra en la sección de "Cartas Árabes" del archivo.

La transcripción del pacto en las dos lenguas está también como apéndice de un artículo de Maria Masala, quien sigue de cerca a Giménez Soler, a pesar de haber calificado su edición de la parte árabe de "trascrizione imperfetta" (Masala, 1993, 318, n.10), copia casi todos sus errores y la empeora añadiendo múltiples erratas nuevas y varios saltos de texto de igual a igual. Esta autora incluye un intento, no muy feliz, de traducción del árabe al italiano.

La parte aragonesa reproduce la fecha de firma por el monarca de Granada, el 4 de mayo de 1405, de una primera versión que Martín el Humano no quiso aceptar. La parte árabe indica que el pacto se firmó el 25 de $r a b{ }^{\imath} I$ de 808 y da la equivalencia de setiembre de 1405 , que corresponde a la ratificación definitiva en Granada.

Hasta ahora, los estudios que se han referido al tratado se han basado en esas ediciones parciales e incompletas y tienen por ello deficiencias. El hecho de que Giménez Soler no tradujera la parte árabe ha sido la causa de que los historiadores no se hayan dado cuenta de que cada una de las dos versiones lleva una fecha distinta. Así Hinojosa (1978, 93-96), al hablar del pacto y resumir sus capítulos, lo data en mayo de 1405 , e incurre en varias confusiones e inexactitudes.

En otro pasaje, Giménez Soler destacó que "una de las cláusulas más discutidas fue la del tiempo que debía durar esta paz; de modo que a Nicolás Pujada se le dieron dos copias, una con un plazo y otra con otro, según consta en las instrucciones que se le dieron" antes de partir hacia Granada; sitúa este hecho (que tuvo lugar el 27 de julio de 1405) en agosto de 1405 (Giménez Soler, 1908, 333). De esta referencia deriva la afirmación que se ve en algunos trabajos, y que no es correcta, según la cual el pacto se habría firmado en agosto de 1405 (López Pérez, 1995, 193; López de Coca, 2001, 249). Masala ya había señalado en 1993 la presencia en el texto árabe de la fecha de la firma final del pacto el 20 de septiembre, pero tal vez su artículo haya tenido poca difusión.

El presente trabajo tuvo su punto de partida en 2017 cuando, como respuesta a la convocatoria de la Commission Internationale de Diplomatique, decidí presentar el análisis diplomático de este documento al congreso que se iba a celebrar en Leipzig en octubre de 2018. En vista de lo que antecede, me pareció que antes de emprender ningún tipo de análisis del tratado o de estudiarlo en cualquiera de sus aspectos convenía preparar una nueva edición de las partes aragonesa y árabe siguiendo criterios actuales. Mi propósito aquí es 
tan sólo el de poner el texto completo del pacto a disposición de la comunidad investigadora y hacer accesible también el contenido de la parte árabe, traduciéndola por primera vez al español. El estudio de los caracteres intrínsecos del pacto, el proceso de su negociación, los personajes implicados, la documentación conservada en relación con él y demás aspectos serán objeto de publicaciones independientes.

\section{ESTRUCTURA DIPLOMÁTICA DEL TRATADO. CARACTERES EXTERNOS}

Se hicieron dos copias bilingües del acta, una para cada una de las partes principales implicadas, las coronas de Aragón y Granada. Es de destacar que no se hizo una tercera copia para el rey de Sicilia. Las lenguas elegidas fueron el árabe clásico y el aragonés.

El soporte es un pergamino de color blanco, que mide $86,5 \mathrm{~cm}$ de altura x 61 $\mathrm{cm}$ de anchura arriba y $62,3 \mathrm{~cm}$ abajo. Su estado de conservación es casi perfecto. Hay que lamentar sólo una arruga horizontal que dificulta leer la línea 18 árabe.

La tinta es de color pardo. El texto está distribuido en dos columnas verticales, sin separación de párrafos en ninguna de las dos; la versión árabe está a la derecha; la aragonesa a la izquierda.

La caja de escritura del texto árabe tiene una anchura de $25,5 \mathrm{~cm}$ y una altura de $50 \mathrm{~cm}$; debajo del texto quedan $30 \mathrm{~cm}$ en blanco. La interlínea es de $1 \mathrm{~cm}$. Tiene 55 líneas de texto.

La caja de escritura del texto romance tiene una anchura de $23,2 \mathrm{~cm}$ y una altura de $76 \mathrm{~cm}$. La interlínea es de $0,55 \mathrm{~cm}$. Tiene 123 líneas de texto.

El margen derecho es de 5,3 cm; el central de $2 \mathrm{~cm}$; el izquierdo de $5,5 \mathrm{~cm}$; el superior de $5,5 \mathrm{~cm}$ en la parte romance y de $6 \mathrm{~cm}$ en la parte árabe. La plica mide $3,8 \mathrm{~cm}$.

Como dice el propio texto, el tratado de paz que nos ocupa es una carta pública, una carta solemne emitida en pergamino, escrita en letra gótica minúscula muy cuidada y limpia y sellada con sello pendiente de cera; es el rasgo principal que la distingue de la carta plomada, además del hecho de llevar anuncio de validación. Pertenece al tipo "notificativo" de carta abierta. Según la versión árabe, se trata de un "escrito" (maktūb); la letra es cursiva magrebí, puntuada y casi totalmente vocalizada.

Las manos que intervinieron en el documento son las de los escribanos, una en cada versión; están además los autógrafos de los dos reyes y el notario y la 'alāma escrita por el soberano de Granada. 
El pergamino tiene una serie de óculos romboidales para los sellos pendientes: cuatro bajo la parte romance y dos en la parte árabe. Giménez Soler $(1908,333)$ dice que aunque no se conservaban los sellos, vio las cintas de seda que los sujetaban, que eran de color amarillo y encarnado en los de los reyes catalano-aragoneses y encarnado muy oscuro en el del rey granadino. Masala también menciona las cintas, en las que además afirma que "si possono vedere le tracce dei sigilli" (Masala, 1993, 318), aunque no especifica de qué materia ni de qué color eran éstos. En la actualidad el pergamino no lleva cintas.

\section{TEXTO DE LA PARTE ÁRABE}

En mi edición he separado las líneas y las he numerado. Reproduzco la grafía del original en todos sus aspectos, incluyendo las vocales y otros signos auxiliares presentes, así como las geminaciones que reflejan la lectura basada en la recitación coránica.

Indicaré en un apartado al final las principales variantes de lectura de las ediciones de Giménez Soler (G) y Masala (M). Ambas ediciones omiten todas las vocales, la hamza y la geminación. Giménez Soler no marca en la edición los cambios de línea; la de Masala los señala con una barra, sin numerarlos. Para no cargar la anotación, no señalo cuando figura en ellas $<y>$ en lugar de alif maqșūra ni, a la inversa, cuando han editado $<\mathrm{y}>$ final sin puntos. 


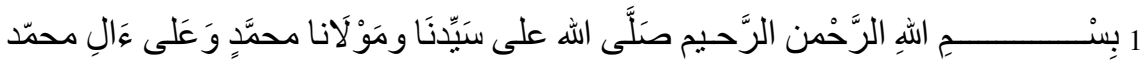
وََّصَحْبِه وَسلَّمَ تَسْلِيمًا

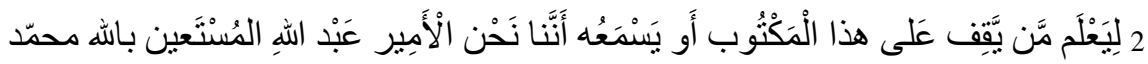

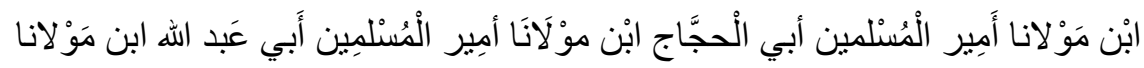

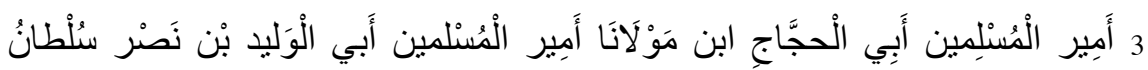

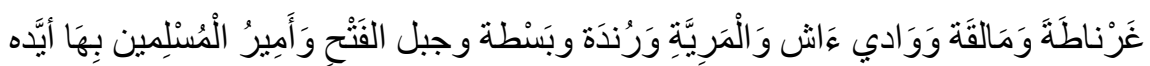
الله ونَصَرهره وحرس جميع ذللك

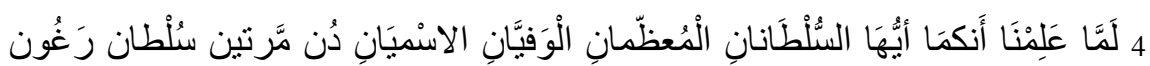

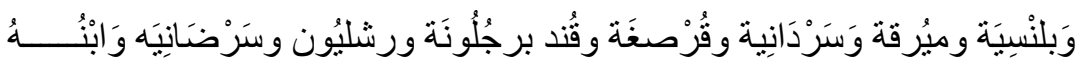

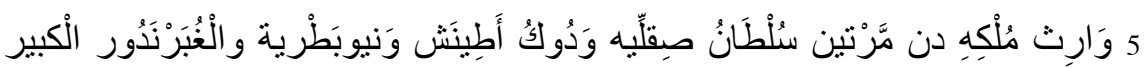

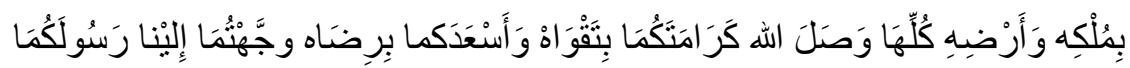

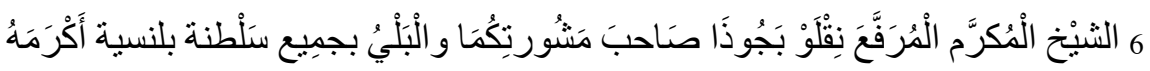

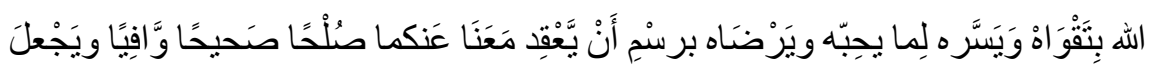

بَيْنَنَا

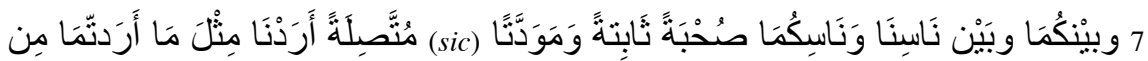

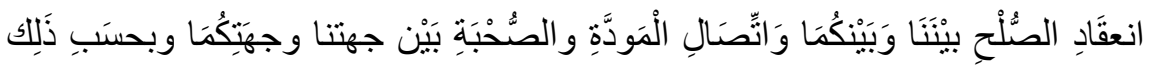

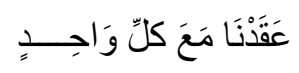

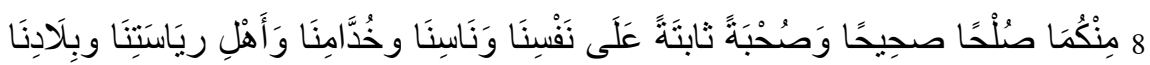

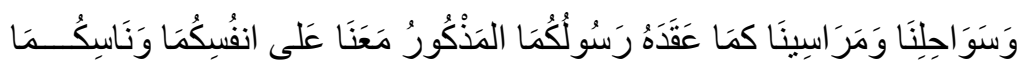

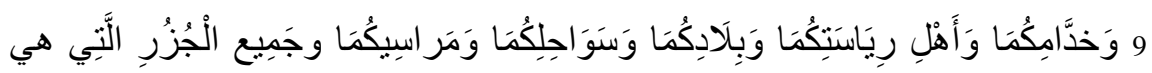

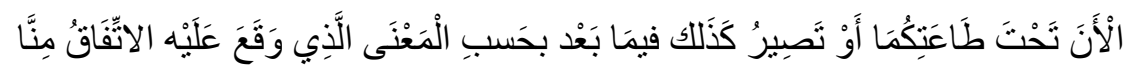

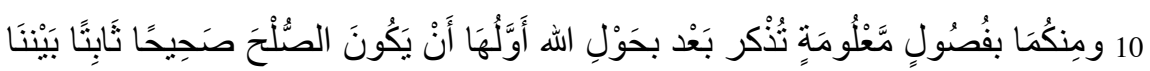

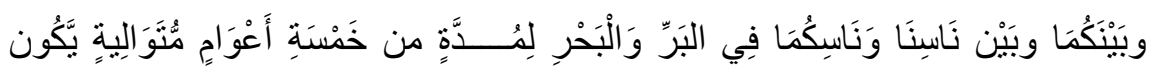

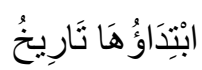




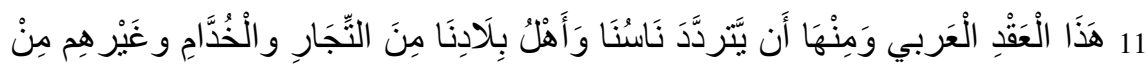

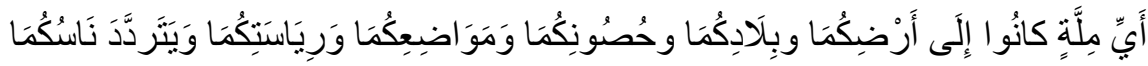

وأَهْلِ

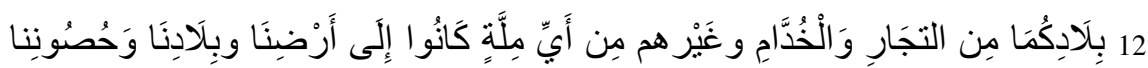

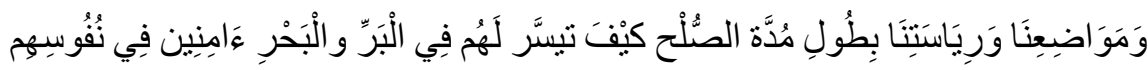

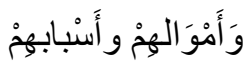

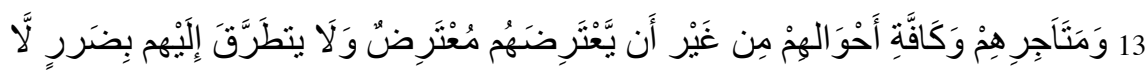

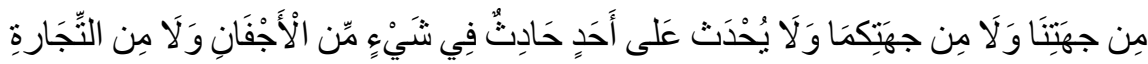

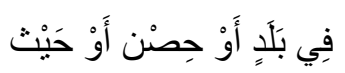

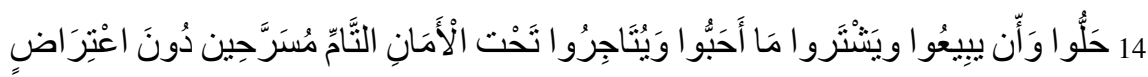

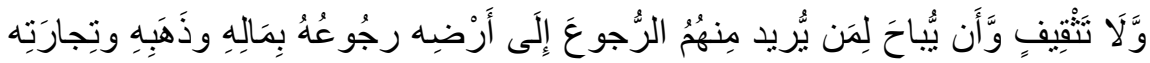
وَأَثْوَابِهِ

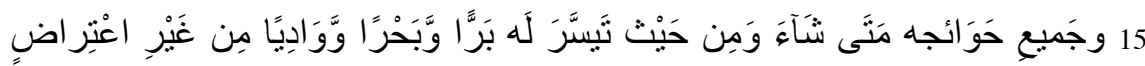

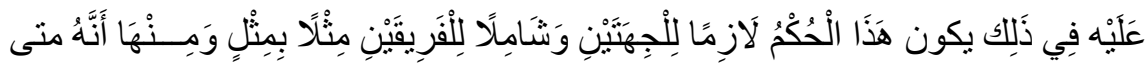
احْنَجْنُمَا

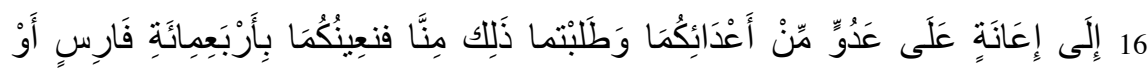

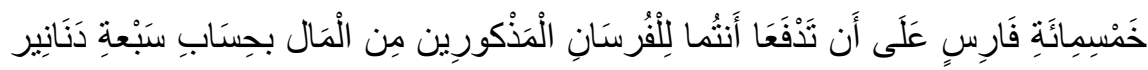
مِن الذَََّبِ الْعَيْن

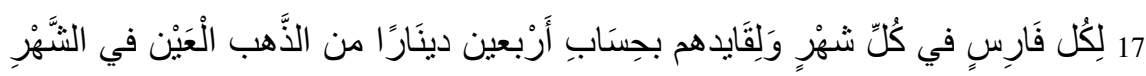

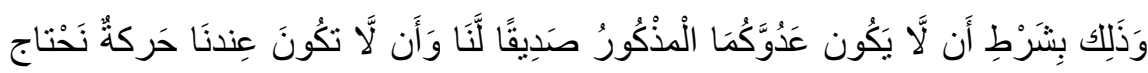
إلْئها الفرسانَ

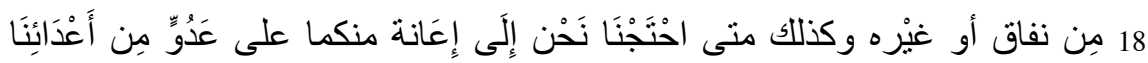

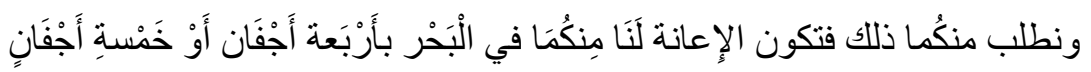




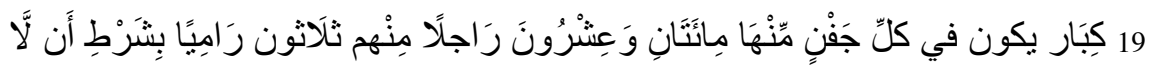

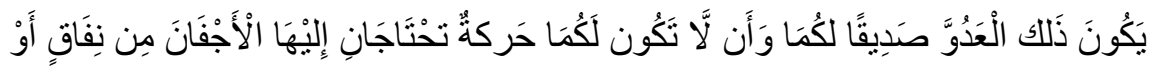
غيْرِ

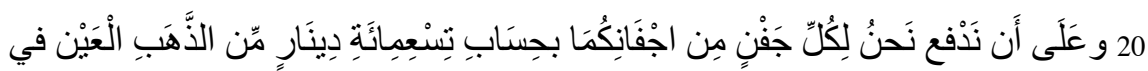

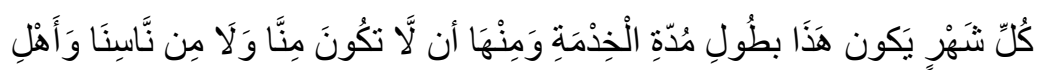

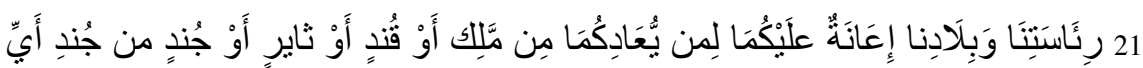

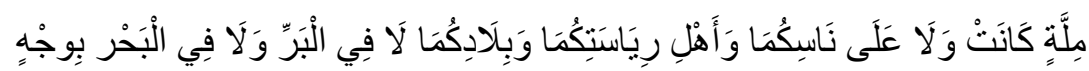

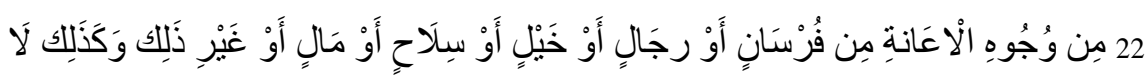

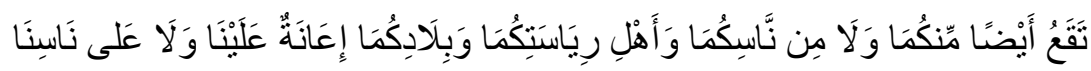

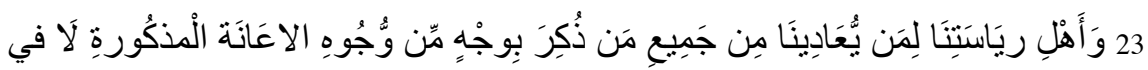

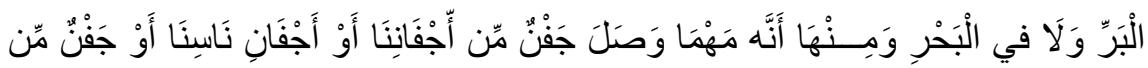
أَجْفَانِكُمَا أَو أَجْفَانِ

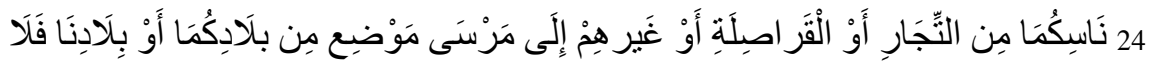

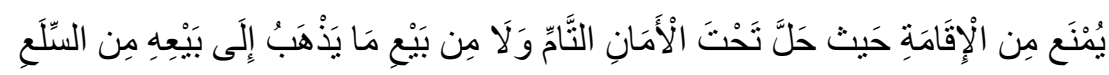

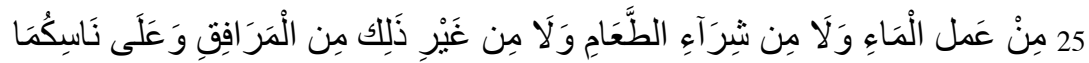

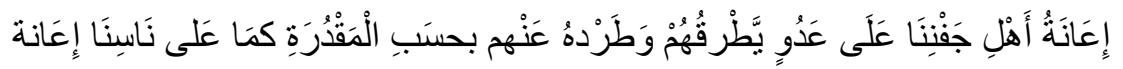
أَهْلِ

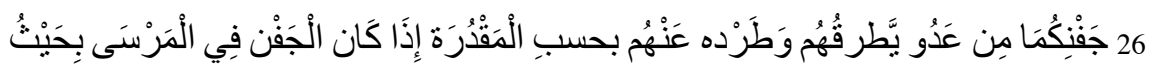

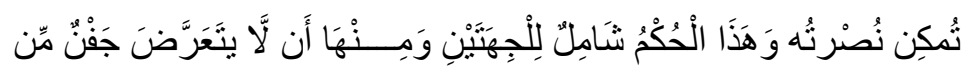
أَجْفَانِكُمَا

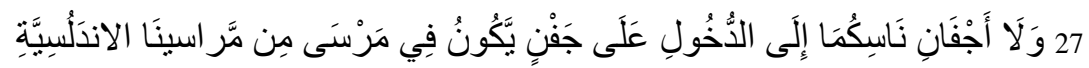

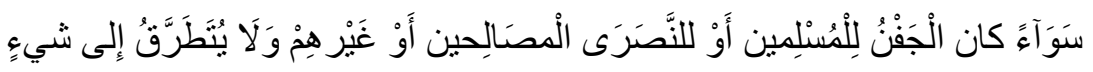

$$
\text { منها بِضَرَرَ }
$$




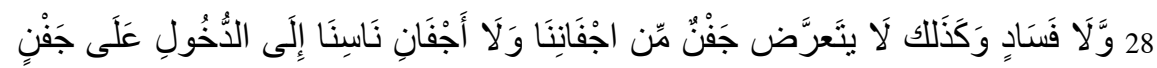

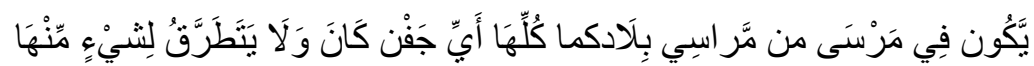

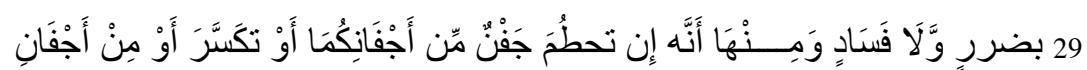

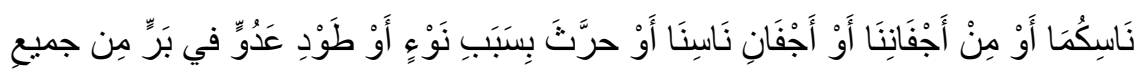

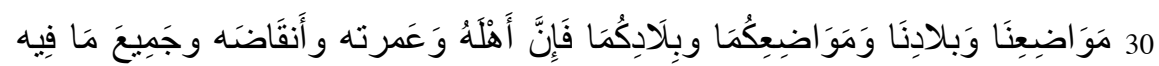

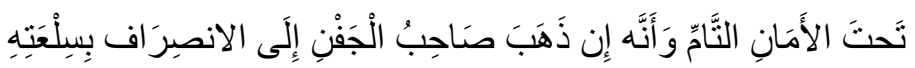

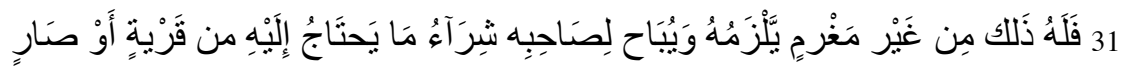

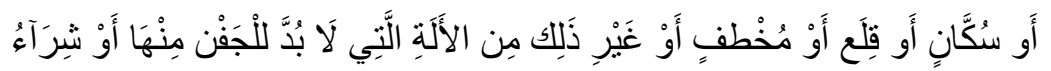

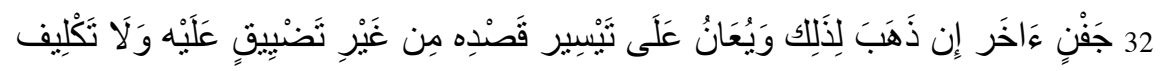

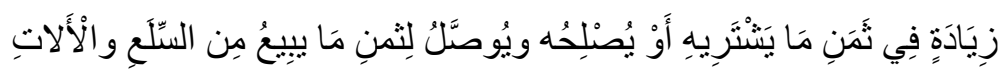

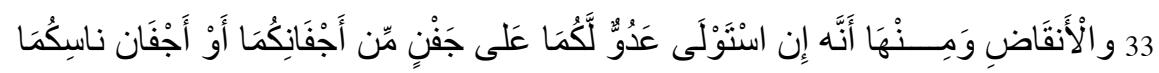

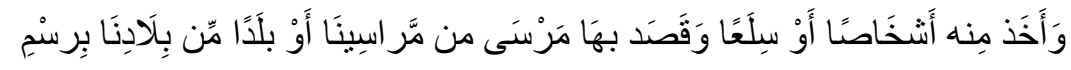

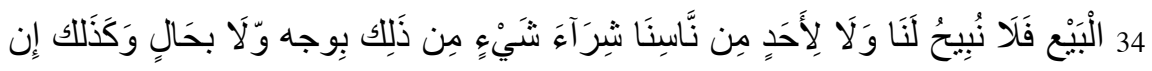

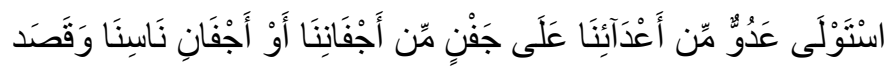

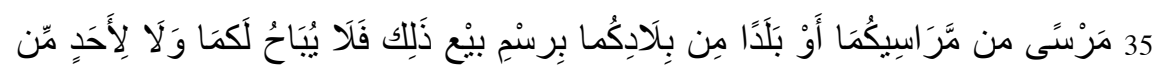

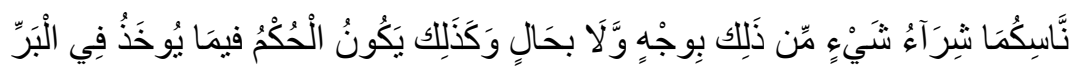

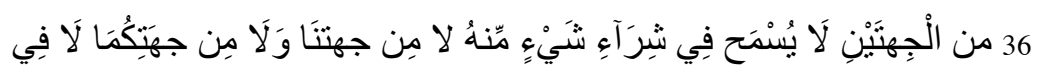

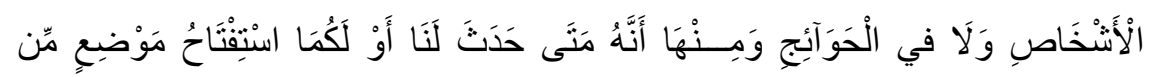

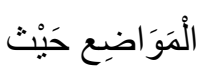

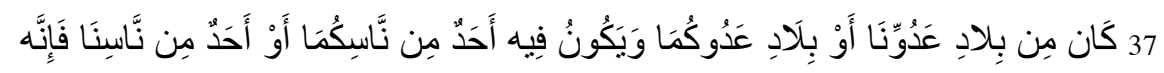

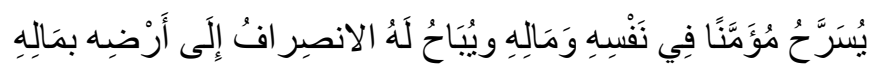

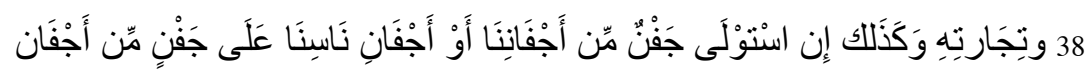

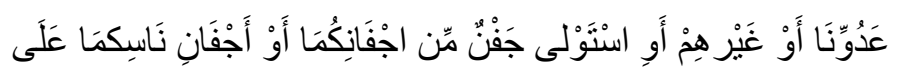




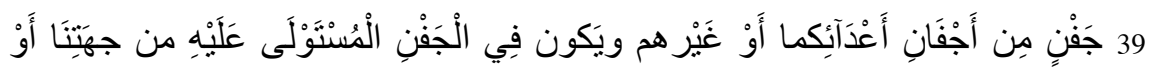

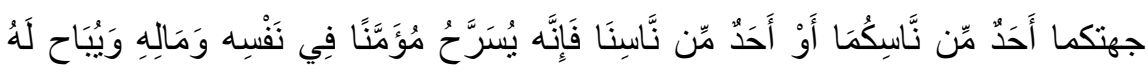
الانصِر اف

40

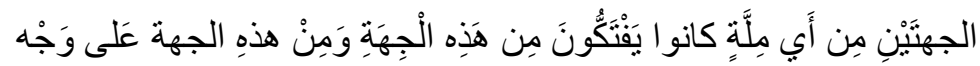

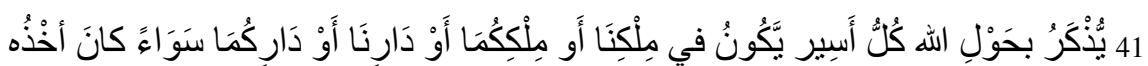

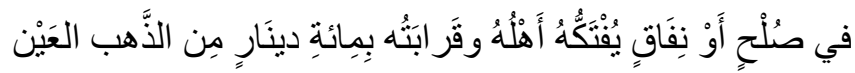

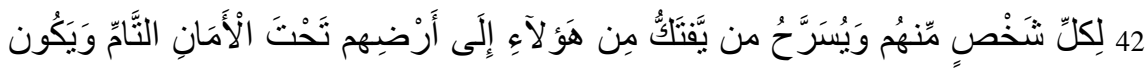

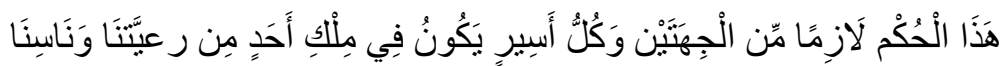

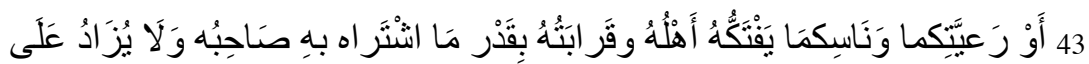

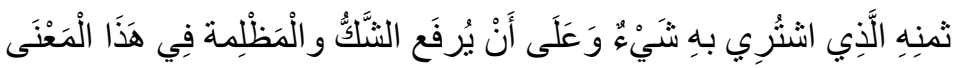

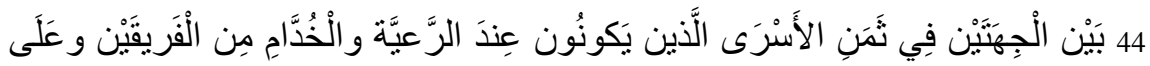

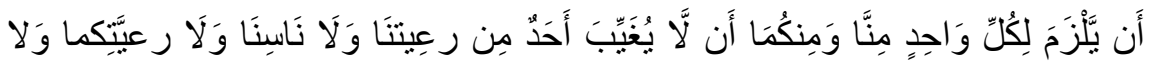

نَاسِكما

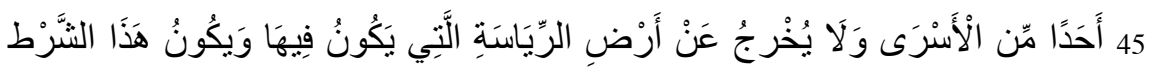

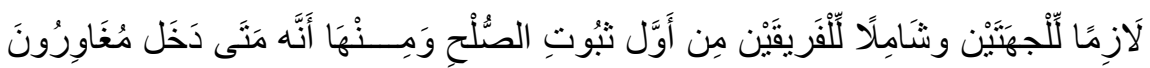
مِنْ أَهْلِ

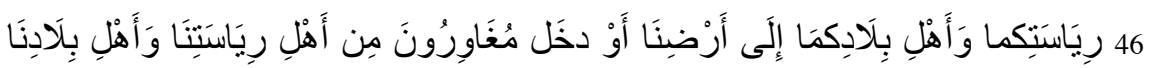

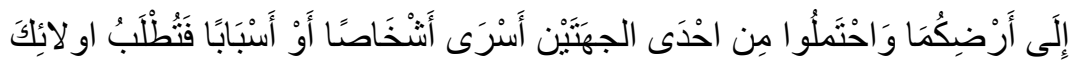

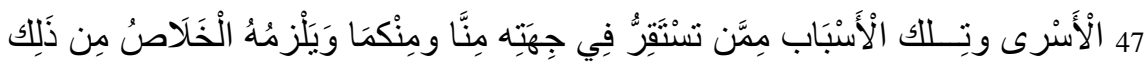

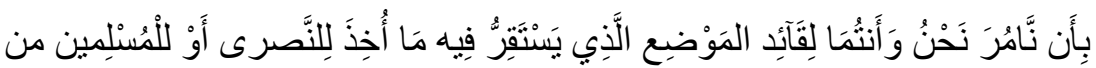
اسير

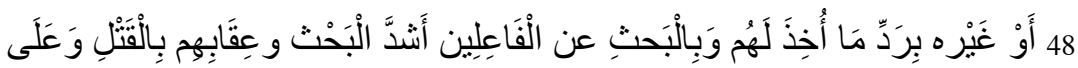

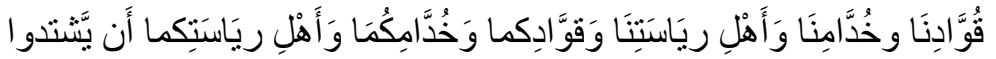




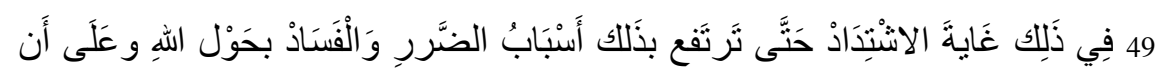

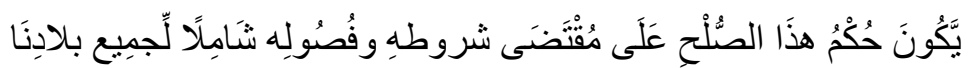

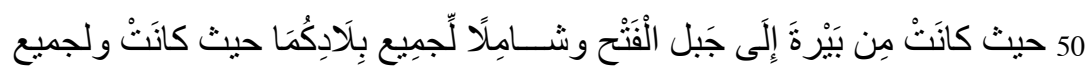

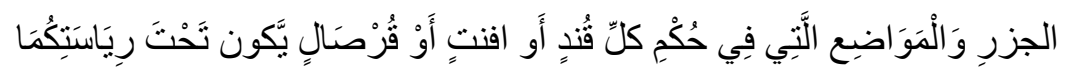

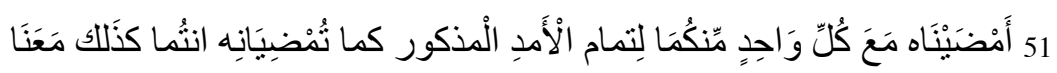

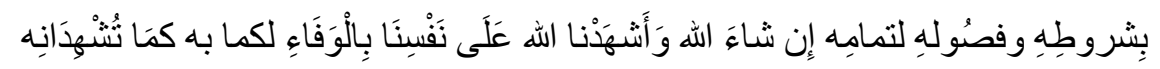

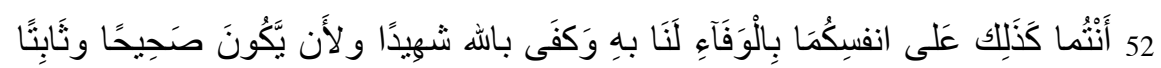

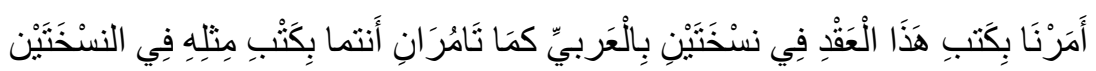

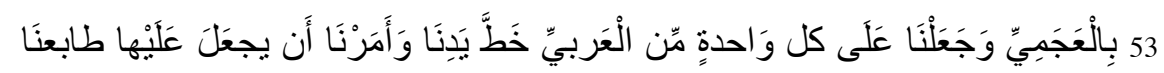

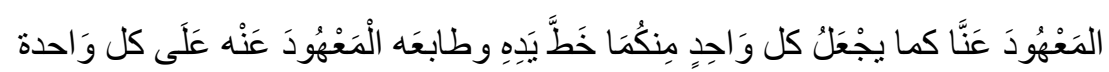
من العجمي (sic) 54 بحول الله لِتكُونَ إِحْدى النُّنْنَتَّنِ عندنَا والاخْرى عِندكما وَكتب في الْخَامِس و العِشرِين

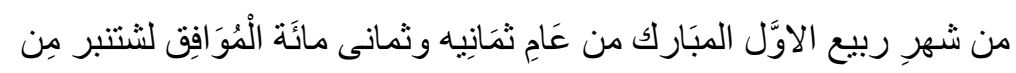

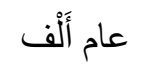

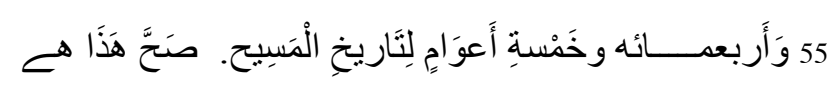




\section{VARIANTES DE LECTURA DE LA PARTE ÁRABE EN LAS OTRAS EDICIONES}

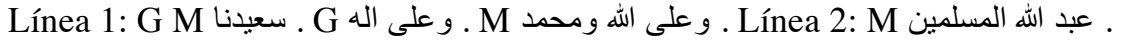

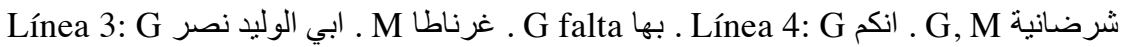

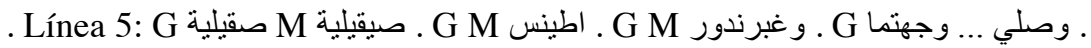

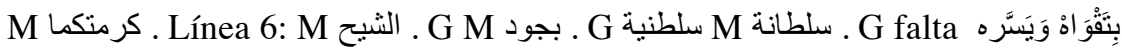

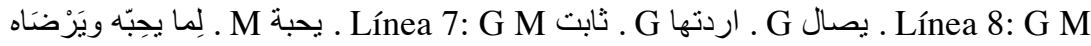

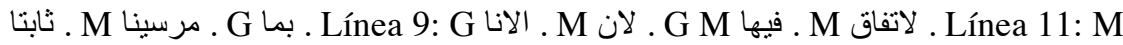

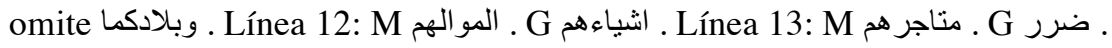

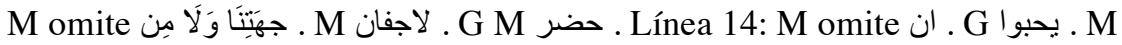

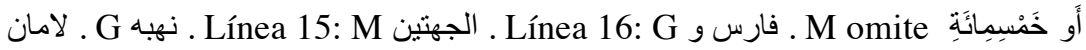

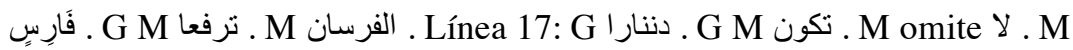

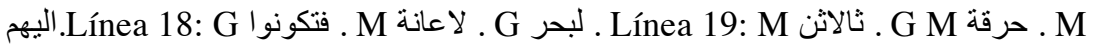

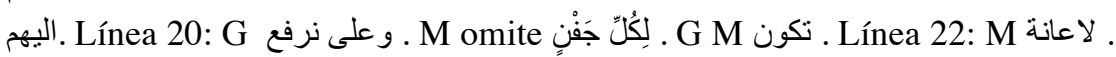

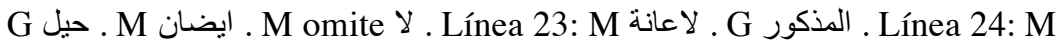

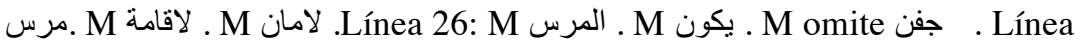

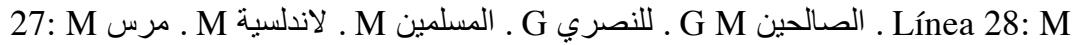

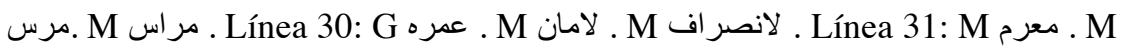

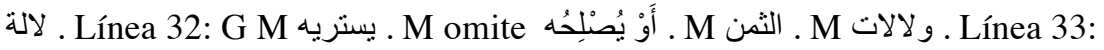

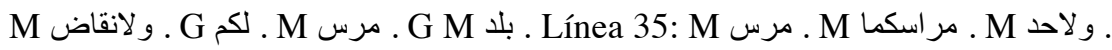

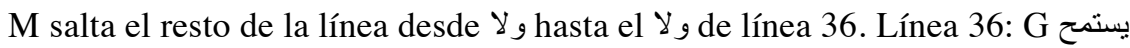

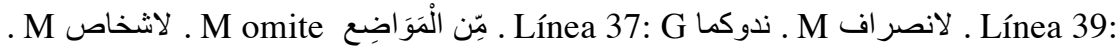

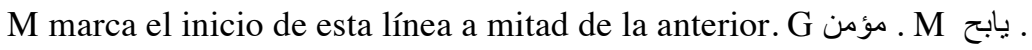

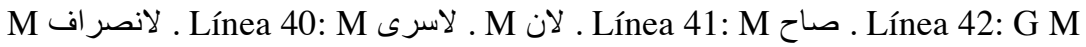

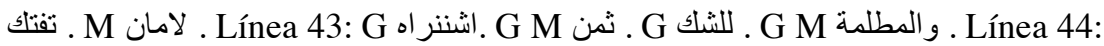

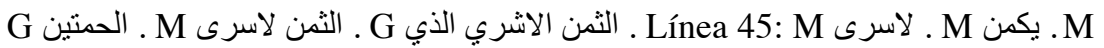

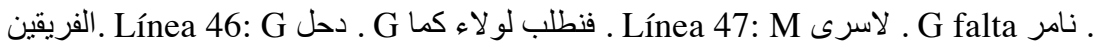

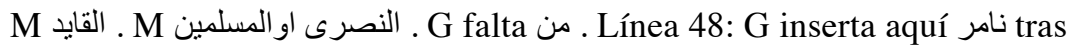

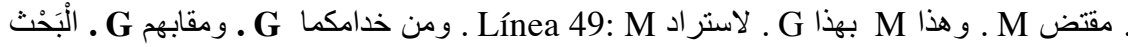

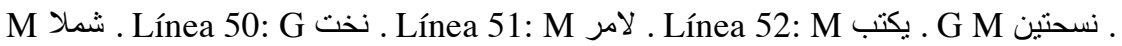

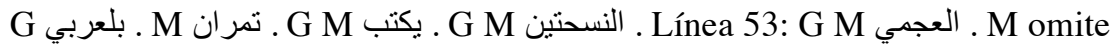

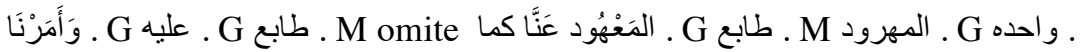

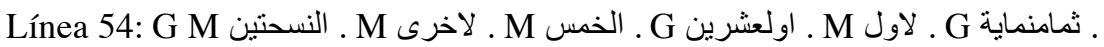




\section{TRADUCCIÓN DE LA PARTE ÁRABE}

$I^{1}$ En el nombre de Dios, el Clemente, el Misericordioso. Dios bendiga y salve a nuestro señor y nuestro dueño Mahoma, a la familia de Mahoma y a sus compañeros.

${ }^{2}$ Sepa quien lea o escuche este escrito que nós el príncipe, siervo de Dios, alMusta 'in bi-llāh, Muhammad hijo de nuestro señor el príncipe de los musulmanes Abū-l-Haŷŷâŷ, hijo de nuestro señor el príncipe de los musulmanes Abū 'Abd Allāh, hijo de nuestro señor $\left.\right|^{3}$ el príncipe de los musulmanes Abū-l-Haŷŷây, hijo de nuestro señor el príncipe de los musulmanes Abū-1-Walīd Ibn Nașr soberano de Granada, Málaga, Guadix, Almería, Ronda, Baza y Gibraltar y príncipe de los musulmanes en ellas, Dios le ayude y le auxilie y guarde todo eso, $\left.\right|^{4}$ cuando supimos que vosotros, oh excelsos, leales, muy realzados soberanos don Martín, soberano de Aragón, Valencia, Mallorca, Cerdeña y Córcega, conde de Barcelona, Rosellón y Cerdaña, y su hijo, $\left.\right|^{5}$ el heredero de su reino, don Martín, soberano de Sicilia, duque de Atenas y Neopatria y gran gobernador en todo su reino y su tierra, Dios prolongue vuestra honra por temerle y os favorezca por satisfacerle, nos habéis enviado a vuestro mensajero, $\left.\right|^{6}$ el magistrado honorable y enaltecido Nicolau Pujada (Niqlaw Baŷū $d \bar{a})$, señor de vuestro Consejo y Baile (al-balyu) en todo el reino de Valencia, Dios le honre por temerle y le facilite lo que ama y le satisface, con la intención de que pacte con nós en nombre vuestro una paz verdadera y leal y establezca entre nós $\mathrm{I}^{7} \mathrm{y}$ vosotros y entre nuestra gente y vuestra gente una amistad firme y un afecto duradero, hemos querido lo mismo que habéis querido vosotros: acordar la paz entre nós y vosotros y prolongar el afecto y la amistad entre nuestra zona y vuestra zona; y para ello hemos acordado con cada uno $l^{8}$ de vosotros una paz verdadera y una amistad firme por nós, nuestra gente, nuestros servidores y los habitantes de nuestro dominio y nuestro país, nuestras costas, y nuestros puertos, como lo pactó con nós vuestro citado enviado, por vosotros, vuestra gente, $I^{9}$ vuestros servidores, la gente de vuestro dominio, vuestro país, vuestras costas, vuestros puertos y todas las islas que están ahora sometidas a vuestra obediencia o lo estarán en el futuro, según el significado sobre el que nos hemos puesto de acuerdo nós y ${ }^{10}$ vosotros, con capítulos conocidos que se mencionarán a continuación, con la ayuda de Dios. El primero es que la paz verdadera y firme entre nós y vosotros, entre nuestra gente y vuestra gente, por tierra y por mar, será por un periodo de cinco años consecutivos, cuyo inicio será la fecha $\left.\right|^{11}$ de este acta en árabe. Otro es que nuestra gente, los habitantes de nuestro país, comerciantes, servidores u otros, sean de la comunidad que sean, irán a vuestra tierra, vuestro país, vuestros castillos, vuestros lugares y vuestro dominio; y que vuestra gente, los habitantes $1^{12}$ de vuestro país, comerciantes, servidores u otros, sean de la comunidad que sean, irán a nuestra tierra, nuestro país, nuestros castillos, nuestros lugares y nuestro dominio durante todo el periodo de la paz, como les resulte más fácil, por tierra y por mar, seguros en sus personas, sus riquezas, sus pertrechos, ${ }^{13}$ sus mercancías y la totalidad de sus circunstancias sin que nadie se lo impida ni les cause perjuicio ni por parte nuestra ni por parte vuestra ni le ocurra a nadie ningún accidente en ninguno de los barcos ni en el comercio, en ninguna 
población o castillo o donde ${ }^{14}$ se establezcan, y que vendan y compren lo que quieran y comercien con total seguridad, libres, sin impedimento ni estorbo, y que a quien quiera regresar a su tierra se le permita volver con su riqueza, su oro, su mercancía, su ropa, $\left.\right|^{15} \mathrm{y}$ todos sus bienes cuando quiera y por donde le convenga, por tierra o por mar o por río, sin que se le impida hacerlo. Esta disposición obliga a las dos partes y engloba a los dos grupos por igual. Otra es que cuando necesitéis ${ }^{16}$ ayuda contra uno de vuestros enemigos y nos la pidáis, os ayudaremos con cuatrocientos o quinientos caballeros, siempre que vosotros paguéis a dichos caballeros en dinero a razón de siete dinares de oro contante $\left.\right|^{17}$ a cada caballero por cada mes, y a su jefe a razón de cuarenta dinares de oro contante al mes; y eso a condición de que dicho enemigo vuestro no sea amigo nuestro y de que no tengamos agitación para la que necesitemos a los caballeros, $\left.\right|^{18}$ como hostilidades u otra cosa; e igualmente cuando necesitemos nós ayuda de vosotros contra uno de nuestros enemigos y os la pidamos, nos ayudaréis por mar con cuatro o cinco naves $\mathrm{I}^{19}$ grandes, en cada una de las cuales haya doscientos veinte peones, treinta de ellos arqueros, a condición de que ese enemigo no sea amigo vuestro y de que no tengáis agitación para la que necesitéis las naves, por hostilidades u otra cosa, ${ }^{20} \mathrm{y}$ siempre que paguemos nós a cada una de vuestras naves a razón de novecientos dinares de oro contante cada mes, durante todo el periodo del servicio. Otra es que no prestaremos ni nós, ni nuestra gente, ni los habitantes ${ }^{21}$ de nuestro dominio y nuestro país ayuda contra vosotros a quien sea enemigo vuestro, sea rey o conde o rebelde o ejército de cualquier comunidad, ni contra vuestra gente y los habitantes de vuestro dominio y vuestro país, ni por tierra ni por mar, con ningún ${ }^{22}$ tipo de ayuda como caballeros o peones o caballos o armas o dinero u otra cosa; e igualmente tampoco habrá ayuda de vosotros, ni de vuestra gente y los habitantes de vuestro dominio y vuestros países contra nós ni contra nuestra gente ${ }^{23}$ y los habitantes de nuestro dominio, para quien sea enemigo nuestro de entre todos los que se han citado, con ninguno de dichos tipos de ayuda, ni por tierra ni por mar. Otra es que si llega una nave de las nuestras o de las de nuestra gente o una nave de las vuestras o ${ }^{24}$ de las de vuestra gente, de comerciantes o de corsarios o de otros, al puerto de un lugar de vuestro país o del nuestro, no se le impedirá permanecer donde se instale, bajo protección completa, ni vender las mercancías que haya ido a vender, ni ${ }^{25}$ tomar agua, ni comprar alimentos ni otros pertrechos, y vuestra gente deberá ayudar a la gente de nuestra nave contra cualquier enemigo que los aborde y alejarlo de ellos según las posibilidades, al igual que nuestra gente deberá ayudar a la gente ${ }^{26}$ de vuestra nave contra cualquier enemigo que los aborde y alejarlo de ellos según las posibilidades si está la nave en el puerto donde sea posible asistirle. Esta disposición engloba a las dos partes. Otra es que no osará ninguna de vuestras naves ${ }^{27} \mathrm{ni}$ de las naves de vuestra gente asaltar ninguna nave que esté en alguno de nuestros puertos de al-Andalus, da igual que la nave sea de musulmanes, de cristianos con los que hay paz o de otros, ni causar a nada daño ${ }^{28}$ ni perjuicio. E igualmente no osará ninguna de nuestras naves ni de las naves de nuestra gente asaltar a una nave que esté en alguno de los puertos de todo vuestro país, sea la nave que sea, ni causar a nada ${ }^{29}$ daño ni perjuicio. Otra es que si se quiebra o se rompe una nave de las vuestras o de las de vuestra gente o de nuestras naves o de las de nuestra gente o encalla a causa de una tempestad o la persecución de un enemigo en la tierra de 
cualquiera ${ }^{30}$ de nuestros lugares y nuestro país y vuestros lugares y vuestro país, su gente, su tripulación, sus restos y todo lo que haya en ella estarán en completa seguridad, y si el dueño de la nave decide irse con sus mercancías, $\left.\right|^{31}$ tendrá derecho a ello sin que se le imponga ninguna gabela, y se le permitirá a su dueño comprar lo que necesite, como vergas, o mástil, o timón o velas u otro pertrecho indispensable para la nave; o comprar $\mathrm{P}^{32}$ otra nave si así lo decide; se le ayudará para facilitarle su voluntad, sin agobiarle ni cobrarle de más en el precio de lo que compre o repare y que cobre el precio de lo que venda de mercancías, pertrechos y ${ }^{33}$ despojos. Otra es que si un enemigo vuestro se apodera de una nave de las vuestras o de las de vuestra gente y coge en ella personas o mercancías y se dirige con ellos a uno de nuestros puertos o a una de nuestras poblaciones con propósito ${ }^{34} \mathrm{de}$ vender, no consentiremos ni a nós ni a ninguno de nuestra gente comprar nada de aquello de ningún modo ni manera e igualmente si se apodera uno de nuestros enemigos de una nave de las nuestras o de las de nuestra gente y se dirige $\left.\right|^{35}$ a uno de vuestros puertos o a una de vuestras poblaciones para venderlo, no se os permitirá a vosotros ni a ninguno de vuestra gente comprar nada de eso de ningún modo ni manera; y la disposición será igual en lo que se coja en la tierra firme ${ }^{36}$ de las dos partes: no se permitirá comprar nada de ello ni por parte nuestra ni por parte vuestra, ni personas ni objetos. Otra es que cuando tenga lugar por parte nuestra o vuestra la conquista de un lugar dondequiera que ${ }^{37}$ sea del país de nuestro enemigo o del país de vuestro enemigo, y haya en él alguien de vuestra gente o alguien de nuestra gente, será liberado, seguro en su persona y su riqueza y se le permitirá marchar a su tierra con su dinero ${ }^{38}$ y sus mercancías. E igualmente si una nave de las nuestras o de las de nuestra gente apresa una nave de las de nuestro enemigo o de otro, o una nave de las vuestras o de las de vuestra gente apresa una nave $~^{39}$ de las de vuestros enemigos o de otros y hay en la nave apresada por nuestra parte o por la vuestra alguien de vuestra gente o alguien de nuestra gente, será liberado, seguro en su persona y sus bienes y se le permitirá marchar $\mathrm{I}^{40}$ a su tierra con su dinero y sus mercancías. Otra es que todos los presos que permanezcan ahora en cada una de las dos partes, sean de la comunidad que sean, serán rescatados de una parte y de la otra parte de la manera $\left.\right|^{41}$ que se mencionará, con la ayuda de Dios: todo preso que esté en poder nuestro o en poder vuestro o en nuestra corte o en vuestra corte, da igual si fue apresado en paz o en guerra, será rescatado por su familia y sus parientes por cien dinares de oro contante $\mathrm{I}^{42}$ por cada uno de ellos y se permitirá al que sea rescatado (ir) a su tierra con total seguridad. Esta disposición obliga a las dos partes. Y todo preso que esté en poder de alguno de nuestros súbditos y nuestra gente $\mathrm{l}^{43} \mathrm{O}$ de alguno de vuestros súbditos y vuestra gente, será rescatado por su familia y sus parientes por la cantidad por la que lo compró su dueño, sin que se añada nada al precio por el que fue comprado; y para evitar la duda e injusticia en este tema $I^{44}$ entre las dos partes acerca del precio de los cautivos que estén en poder de los súbditos y servidores de los dos grupos, se obliga cada uno de nosotros y de vosotros a (vigilar que) no oculte ninguno de nuestros súbditos ni de nuestra gente ni de vuestros súbditos ni de vuestra gente $\mathrm{l}^{45}$ a ninguno de los presos y no se saque de la tierra del dominio en que esté; esta condición es válida para las dos partes y engloba a los dos grupos, desde el principio del establecimiento de la paz. Otra es que cuando entren almogávares de la gente $\mathrm{l}^{46} \mathrm{de}$ vuestro dominio y gente de vuestro país en nuestra tierra o entren almogávares de la 
gente de nuestro dominio y gente de nuestro país en vuestra tierra y se lleven de una de las dos partes personas presas o cosas, serán reclamados esos $1^{47}$ presos y esas cosas a quien (los) tenga en su parte de nós y de vosotros y tendrá que librarlo, puesto que ordenaremos nós y vosotros al alcaide del lugar en que se encuentre lo que se les cogió a los cristianos o a los musulmanes, preso $\left.\right|^{48} \mathrm{u}$ otra cosa, la devolución de lo que se les cogió, la búsqueda con toda diligencia de los responsables y su condena a muerte. Nuestros alcaides, nuestros servidores y la gente de nuestro dominio, vuestros alcaides, vuestros servidores y la gente de vuestro dominio tienen que esforzarse $\mathrm{I}^{49}$ al máximo para evitar así las causas del daño y el perjuicio, con la ayuda de Dios. Y la disposición de esta paz, según dictan sus condiciones y sus capítulos será general para la totalidad de nuestro país, $\left.\right|^{50}$ dondequiera que sea, desde Vera a Gibraltar, y general para todo vuestro país dondequiera que sea y para las islas y los lugares que estén a las órdenes de cada conde o infante o corsario que esté bajo vuestro dominio. ${ }^{51}$ Lo hemos firmado con cada uno de vosotros hasta el término del plazo citado como lo firmáis vosotros dos igualmente con nós con sus condiciones y sus capítulos hasta su conclusión, si Dios quiere. Hemos puesto a Dios por testigo sobre nós de seros leal a él, igual que testimoniáis ante Él $1^{52}$ también vosotros dos sernos leales a él, pues basta con Dios como testigo. Para que esté confirmado y firme hemos ordenado escribir este acta en dos copias en árabe, como vosotros ordenaréis escribir lo mismo en las dos copias $1^{53}$ en romance; y hemos puesto sobre cada una de las árabes la letra de nuestra mano y hemos ordenado que se ponga sobre ella nuestro sello conocido, como pondrá cada uno de vosotros dos la letra de su mano y su sello conocido sobre cada una de las romances, $~^{54}$ con la ayuda de Dios, para que nós tengamos una de las dos copias y vosotros la otra. Se escribió a veinticinco del mes bendito de $r a b \bar{l}^{\prime} I$ del año ochocientos ocho, que corresponde a setiembre del año mil $\left.\right|^{55}$ y cuatrocientos cinco años de la fecha del mesías. Esto es correcto.

\section{TEXTO DE LA PARTE ARAGONESA*}

$I^{1}$ En el nombre de nuestro senyor Dios. Sea a todos manifiesto quantos esta carta

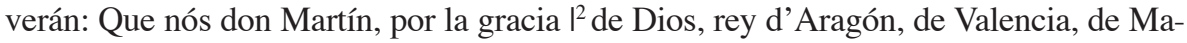
llorquas, de Cerdenya e de Córcega e comte de Barchinona, de Rosselló e de $l^{3}$ Cerdanya. E nós, don Martín, por aquella mesma gracia, rey de Sicilia e duch de Athenas e de Neopatria e del $I^{4}$ dito muyt excellent príncep e senyor don Martín, rey d'Aragón, primogénito e en todos sus regnos e tierras gover ${ }^{5}$ nador general. Considerantes que vós, muyt alto príncep don Mafomat, fillo del rey Abolageig, fillo del rey $l^{6}$ Abiabdile Abolageig, fillo del rey Abilhualit Abenatany, rey de Granada, de Málica, de Codeix, d'Almaría, de $1^{7}$ Ronda, de Basta e de Gibaltar, havedes enviado a nós, dito rey d'Aragón, por mandadero vuestro, Abulcacim, fillo del $I^{8}$ alcayde de Málica, cavallero e consellero vuestro,

* En la transcripción del documento normalizo las mayúsculas y minúsculas, desarrollo las abreviaturas e introduzco acentos, apóstrofo, guión y punto volado, así como puntuación. 
por tractar e fazer que entre nós, ditos reyes, e los vassallos e súbditos $l^{9}$ nuestros e de cadauno de nós e vós, dito rey don Mafomat, e los vassallos e súbditos vuestros haya buena paz e amistança. $\left.\right|^{10}$ Por aquesto querientes, pues vós lo queredes, haver paz e amistat con vós, por tenor de la present carta femos e firmamos paz e amistat con vós, dito rey de $\mathrm{I}^{11}$ Granada, segund en la forma e manera concordada entre nós e vós en ciertos capítoles del tenor seguient:

Primerament. Que entre nós, ditos ${ }^{12}$ reyes d'Aragón e de Sicilia, e vós, dito rey de Granada e districtuales, e sotsmesos de cada uno de nós se faga buel ${ }^{13}$ na paz e firme amistança, duradera por cinquo anyos primero vinientes, contaderos del día adelant que vós, I $^{14}$ dito rey de Granada, hauredes feyta e firmada semblant paz e amistança de aquesta.

Item. Que todos e cadaul ${ }^{15}$ nos mercaderos e otros sotsmesos de nosotros, rey d'Aragón e rey de Sicilia, puedan por todo el tiempo de la dita $I^{16}$ paz e aquella durant entrar e estar comprando, vendiendo e mercadiando e en otra manera franchament e segural ${ }^{17}$ e salva, sienes contrast o embargo, toda vegada que bien visto les será, con todas e cadaunas fustas, mercaderías, $\left.\right|^{18}$ monedas, ropas e otras cosas e bienes, en e por todos e cadaunos castiellos, ciudades, villas e logares e senyoría $~^{19}$ de vós, dito rey de Granada, por tierra e por mar e por agua dolç, e d'aquellas exir e sacar-ne oro e todas e cal ${ }^{20} \mathrm{dau}-$ nas mercaderías, cosas e bienes suyos, e tornar en la senyoría de cadauno de nós, ditos reyes d'Aragón e de Sicilia, $\left.\right|^{21}$ e en aquellas otras partidas que·s querrán, a su francha e líbera voluntat. E semblantment puedan fer aquello mis ${ }^{22}$ mo los súbditos de vós, dito rey de Granada, en e por los castiellos, ciudades, villas, lugares e senyoría de nós, ditt ${ }^{23}$ os reyes d'Aragón e de Sicilia.

Item. Que si vós, dito rey de Granada, demandaredes a nós, ditos reyes de ${ }^{24}$ Aragón o de Sicilia, ayuda ni socorro de gentes, que nós siamos tenidos durant la dita paz ayudar por mar a $1^{25}$ vós, dito rey de Granada, cuentra vuestros enemigos, empero que no sían amigos de nós, ditos reyes d'Aragón e de ${ }^{26}$ Sicilia, de quatro o çinquo gualeras armadas e exarciades, en cada una de las quales haya XXX ballesteros, e con $\mathrm{I}^{27}$ aquellos cumplimiento a dozientes vint hombres, pagando empero ad aquellos vós, dito rey de Granada, su sueldo $\left.\right|^{28}$ complidament, a razón de DCCCC doblas d'oro por cada mes a cadauna gualera de tanto tiempo como servirán. ${ }^{29} \mathrm{E}$ assín mismo vós, dito rey de Granada, siades tenido fer ayuda a nós, ditos reyes d'Aragón e de Sicilia, si la de ${ }^{30} \mathrm{man}$ daremos, cuentra enemigos nuestros, empero que no sían vuestros amigos, de CCCC o cinchicentos hombres de cavallo, $\left.\right|^{31}$ pagando ad aquellos su sueldo entregament, y es assaber: al capitán XXXX dobles d'oro, e a cadauno hombre de $1^{32}$ cavallo VII doblas por cada mes de tanto tiempo como servirán, entendido e declarado empero que la dita ayuda $\left.\right|^{33}$ fagamos nós, ditos reyes de Aragón e de Sicilia, de las ditas gualeras nós no haviendo-las mester por razón de ${ }^{34}$ guerra o de otra necessidat. E vós, dito rey de Granada, la fagades de los ditos hombres de cavallo no haviendo- $\left.\right|^{35}$ los mester por guerra o por otra razón necessaria o urgent.

Item. Que durant la dita paz nós, ditos reyes d'Aragón ${ }^{36}$ e de Sicilia, o algunos vassallos o sotsmesos nuestros, no fagamos valença o ayuda a algún rey o príncep cuentra $\left.\right|^{37}$ vós, dito rey de Granada, en alguna manera. E semblantment vós, dito rey de Granada, 
no podades fazer valença $\left.\right|^{38} \mathrm{o}$ ayuda a algún rey o príncep en alguna manera cuentra nós, ditos rey d'Aragón e de Sicilia.

Item. Que todas fustas $1^{39}$ de cossarios vassallos de nós qui arribarán en las mares, puertos o playas de vós, dito rey de Granada, ${ }^{40}$ sían bien acullidas en aquellos, e no les sea vedado en alguna manera allí arribar e estar, antes puedan prender-hi aguas ${ }^{41}$ e comprar vituallas e otras cosas, e síen allí emparados, mantenidos e deffendidos cuentra todos enemigos nuestros e aquesto $\mathrm{I}^{42}$ mismo sía servado a los vassallos e sotsmesos de vós, dito rey de Granada, en las mares, portos e playas de nós ditos reyes ${ }^{43}$ d'Aragón e de Sicilia.

Item. Que algunas fustas marítimas de nós, ditos reyes, o de nuestros vassallos o sotsmesos, no daml ${ }^{44}$ nifiquen algunas fustas en algunos puertos, playas o marítimas de vós, dito rey de Granada. E semblantment sia fey ${ }^{45}$ to e servado en los puertos, playas e marítimas de la senyoría de nós, ditos reyes d'Aragón e de Sicilia, de las fustas de vós, ${ }^{46}$ dito rey de Granada, e de vassallos vuestros.

Item. Que en caso que por encalç de enemigos o por fortuna de tiempo all ${ }^{47}$ gunas fustas de nós, ditos reyes d'Aragón e rey de Sicilia, o de cadauno de nós e de vasallos e sotsmesos nuestros, en quall ${ }^{48}$ quiera manera ferissen o crebassen en qualsequiera playa o puerto o marítima de la senyoria de vós, dito rey de Granal ${ }^{49} \mathrm{da}$, sían las ditas fustas, con las personas e bienes que·y serán, salvas e segurament guardadas e conservadas, e puedan, si querrán, $\left.\right|^{50}$ allí vender sus mercaderías e cosas; e los de aquella tierra sían tenidos darles toda favor a cobrar aquello que perdido haurán ${ }^{51}$ por crebamiento de las fustas e los precios de las cosas vendidas, e d'allí se'n pueda partir e yr con todo lo suyo salvament e se ${ }^{52}$ gura, sines pagar algun dreyto por la dita razón e sines otra vexación; e no-res-menos puedan allí comprar por precios razo ${ }^{53}$ nables e levarse'n árboles, anthenas, goviernos, áncoras, velas, ruvones, e otras cosas necessarias ad aquellas fus ${ }^{54}$ tas, e las mercaderías e otras cosas que bien visto les será, franchas e quitias de todos dreytos. E aquestas mismas cosas ${ }^{55}$ sían servadas a las fustas de vós, dito rey de Granada, e de vassallos e sotsmesos vuestros, en las playas, puertos e marítimas $\left.\right|^{56}$ de la senyoría de nós, ditos reyes d'Aragón e de Sicilia.

Item. Que si enemigos de vós, dito rey de Granada, haurán apresonal ${ }^{57}$ dos e querrán vender algunos vassallos vuestros en algunos puertos, playas, o marítimas de la nuestra senyoría, que nós o algunos vas ${ }^{58}$ sallos nuestros no podamos comprar ne fer comprar en alguna manera los ditos cativos, robas o mercaderías o cosas algunas $1^{59}$ de aquellos. E aquesto mismo sía servado en vassallos de nós, ditos reyes, por vós, dito rey de Granada, e vassallos vuestros.

${ }^{160}$ Item Que si durant la dita paz s'esdevendrá que nós o vassallos nuestros conquistemos alguna ciudat, castiello, villa o lugar, ${ }^{61}$ o prengam alguna fusta de christianos o otra de qualsequiere nación de gentes, e en aquella presón e conquesta serán atrobadas ${ }^{62}$ algunas personas de vós, dito rey de Granada, o bienes de aquellos, que aquellas todas personas e bienes sían e finquen asse ${ }^{63}$ gurados e soltos e delliurados, e se'n puedan hir las personas e seyer levados los bienes en qualsequiere lugar salvament e ${ }^{64}$ segura. E aquesto mismo sía feyto e servado en las personas de la senyoría de nós, ditos reyes d'Aragón e de Sicilia, en caso de ${ }^{65}$ semblant conquesta o presión por vós, dito rey de Granada. 
Item. Que por mayor tranquil·litat de la dita paz, e esquivar toda $\left.\right|^{66}$ occasión de lesión de aquélla, todos los cativos de la tierra e senyoría de nós, ditos reyes d'Aragón e de Sicilia, de qualsequiera ${ }^{67}$ ley o secta, que entro al día que la dita paz será firmada con todo acabamiento serán estados presos o acativados por quienquiera en quall ${ }^{68} \mathrm{se}$ quiera partidas e en qualquiera manera, assín en tiempo de guerra como de paz, e sían e estén presos en qualsequiera manera ${ }^{69}$ en poder de vós, dito rey de Granada, sían, encontinent e de feyto que demandados serán, restituidos e liurados a los amigos $\mathrm{I}^{70} \mathrm{de}$ aquéllos, yés a saber: cadauno de los ditos cativos por .C. doblas, e los que serán presos en poder de vassallos de vós, ${ }^{71}$ dito rey de Granada, sean, encontinent e de feyto que demandados serán, restituidos e liurados a los amigos de cadauno de los $1^{72}$ cativos por el precio que costado haurán a sus senyores, sines toda dilación, cessantes toda frau e ficción. E aquesto mismo $\left.\right|^{73}$ en semblant manera sía feyto e servado por nós, ditos reyes d'Aragón e de Sicilia, e nuestros vassallos e sotsmesos, en los ditos cal ${ }^{74}$ tivos suyos, vassallos de vós, dito rey de Granada. E a fueragitar toda frau, collusión e calumpnia que fer o seguir se podie ${ }^{75}$ sen sobra la manifestación fazedera de cadauno de los ditos cativos e sobre los verdaderos precios de aquéllos, sía estretament $1{ }^{76}$ provehido por nós, ditos reyes, e vós, dito rey de Granada, yés assaber por cadauno en su tierra e senyoria, que alguno de los ditos $1{ }^{77}$ cativos en alguna manera directa o indirecta, ficta o vertadera, manifiesta o escondida, no sea sacado fuera el regno en el ${ }^{78}$ qual yés de present, ne encara vendido o transportado por nós, ditos reyes d'Aragón e de Sicilia, o vassallos o subditos $1^{79}$ nuestros, ne por vós, dito rey de Granada, o vassallos o súbditos vuestros, ad·alguna persona dentro o fuera los regnos, por tal que, $\left.\right|^{80}$ firmada la dita paz, sian trobados todos e cadauno de los cativos sobreditos en la manera que son de present en poder de aquellos ${ }^{81}$ qui los possedecen e tienen.

Item. Que si durant la dita paz algunos almugáveros o collarados de la senyoría de vós, dito ${ }^{82}$ rey de Granada, entrarán en la senyoría de nós, ditos reyes, e cativarán algunas personas e aquéllas se’n levarán en Granal ${ }^{83} \mathrm{da}$, o en otro qualsequiere lugar de vuestra senyoría, que vós, dito rey de Granada, siades tenido mandar a los vuestres alcaydes ${ }^{84}$ de Bera e de Béliz el mayor, e a sus logares-tenientes, e a cadauno d'ellos, que prengan e hayan a su mano e poder aquellos $\left.\right|^{85}$ ditos collarados o almogáveres, e liuren aquéllos de continent a muert corporal e restituescan al Governador de Oriola o ${ }^{86}$ lugartenient de aquello a aquellos qui dyputados hi serán por el consello de aquella vila, realment e de facto, encontinent que $\mid{ }^{87}$ requeridos ne serán todos los ditos christianos que sían estados cativados con todos sus bienes e cosas. E semblantment ${ }^{88}$ sía feyto e firmado por nós, ditos reyes d'Aragón e de Sicilia, en los vassallos de vós, dito rey de Granada, mandando al $1{ }^{89}$ dito Governador nuestro de Oriola, o lugartenient de aquéll, e a los deputaderos a aquesto por el consello de Oriola, la pul ${ }^{90}$ nición de los ditos malfaytores vassallos nuestros, e restitución de los cativos e bienes d'ellos a los ditos alcaydes de Béliz el mal ${ }^{91}$ yor e de Bera. E por tal que la dita paz segunt los capítoles preinsertos valga, e tenga e haya toda firmeza, efficacia e $1^{92}$ valor, por todo el tiempo de los ditos cinquo anyos, con la present carta nuestra loamos nós, ditos reyes, en quanto a de nós $\mathrm{I}^{93} \mathrm{~s}$ 'estiende, e affirmamos la dita paz segunt que desuso se contiene; e prometemos en nuestra bona fe reyal, en mano e poder $1^{94}$ del notario e secretario 
nuestro, dius scripto, recibient aquestas cosas por vós o por quales quiera otros de qui sía e pueda seyer interés, ${ }^{95}$ que la dita paz e la dita ayuda, con todas e cadaunas cosas en los ditos capítoles contenidas, tenrremos e observaremos, ${ }^{96}$ tener e observar faremos, e no cuentra-beniremos, ne algú contravenir lexaremos por alguna causa o razón.

En testimonio ${ }^{97}$ de la qual cosa mandamos seyer feyta la present carta nuestra pública, sellada con el siello de la maiestat de nós, dito rey d'Aral ${ }^{98}$ gón, e con el siello común de nós, dito rey de Sicilia, en pendient, e signada de nuestras manos. E no-resmenos mandamos ${ }^{199}$ seyer-ne feyta otra carta semblant de aquesta, por tal que nós tengamos la una, e vós la otra, e es tal la una como la ${ }^{100}$ otra, en christianisco e en morisco.

Feyto fue aquesto en la ciudat de Barchinona, a quatro días del mes de mayo, en el anyo $\left.\right|^{101}$ de la natividat de nuestro Senyor mil quatrocientos cinquo, e del regno de nós, dito rey d'Aragón, dezeno, e de nós, dito $\left.\right|^{102}$ rey de Sicilia, quatorzeno.

${ }^{103}$ Signo + de don Martín por la gracia de Dios rey d'Aragón, de Valencia, de Mallorquas, de Cerdenya e de ${ }^{104}$ Córcega e comte de Barchinona, de Rossellón e de Cerdanya, qui aquesto atorgamos e firmamos, e el siell ${ }^{105}$ lo de la nuestra maiestat en pendient havemos mandado aquí seyer puesto. Rex Martinus.

${ }^{106}$ Signo + de don Martín, por aquella mesma gracia, rey de Sicilia e duch de Athenas e de Neopatria, e del $\mathrm{I}^{107}$ dito muyt excellent príncep e senyor don Martín, rey d'Aragón, primogénito e en todos sus $\left.\right|^{108}$ regnos e tierras governador general, qui assín mismo aquesto atorgamos e firmamos e el siello nuestro ${ }^{109}$ en pendient havemos mandado aquí seyer puesto. Rex Martinus.

${ }^{110}$ Testimonios qui fueron presentes a la firma del dicto senyor rey d'Aragón son l'egregio don Jayme, fillo del comte d'Urgel, ${ }^{111}$ e don Jayme de Pradas, e mossén Guerau Alamany de Cervelló, governador de Catalunya, conselleros del senyor rey d'Al'12 ragón.

${ }^{113}$ Testimonios qui fueron presentes a la firma del dito senyor rey de Sicilia son 1'egregio don Jayme de Pradas, e mossén ${ }^{114}$ Johan Ferrández d'Eredia, e mossén Sancho Roiz de Liori, conselleros e camerlenques del dito senyor rey de Sicilia.

${ }^{115}$ Sig + no de mí Johan de Tudela, de los ditos muy excellentes príncipes e senyores, rey d'Aragón e rey de Sicilia, secretario, qui $\left.\right|^{116}$ de mandamiento de-los ditos senyores a las cosas sobreditas present fue, e aquéllas escrevir fiz. Con rasos e emendados $\left.\right|^{117}$ en la X e XI líneas do dize «por tenor de la present carta femos e firmamos paz e amistat con vós, dito rey $\left.\right|^{118}$ de Granada, segund en la forma e manera concordada entre nós e vós» e en la XXXXII líneas do se dize «a los» e I ${ }^{119}$ en la LX e LXVI ${ }^{1}$ líneas do se contiene «e d'aquell o ad-aquellos» et çierre.

$\mathrm{I}^{120}$ [En el interior de la plica:] Dominus Rex Aragonum et dominus Rex Sicilie

${ }^{121}$ mandarunt mihi Iohanni de Tudela

$\mathrm{I}^{122}$ in cuius posse firmarunt

${ }^{123}$ Probatus. In proprium primo.

\footnotetext{
${ }^{1}$ En realidad la corrección está en la línea 86.
} 


\section{VARIANTES DE LECTURA EN LAS OTRAS EDICIONES DE LA PARTE ARAGONESA}

( $\mathrm{B}=$ Bofarull; $\mathrm{G}=$ Giménez Soler; $\mathrm{M}=$ Masala $)$

Línea 2: tras d'Aragón, G sustituye el resto de dominios por puntos suspensivos. Línea 3: G E nos Don Martín... Rey de Sicilia... Línea 4: G reynos. Línea 6: M Abilhualid; G Abennatany M Abenarany; mala copia por Abenaçary. G Granada... havedes; M Codeiy; Línea 7: B Basca; G Abalcacim. Línea 10: G esto; G pas; Masala omite desde el primer "con vos" hasta el "con vos" a final de línea. Línea 13: G cinco. Línea 14: G pas. Línea 17: G contrart; G cada una. Línea 19: M A d.aquellas. Línea 21: G voluntad. Línea 22: G senyorio. Línea 24: G seamos. Línea 25: G nos dito. Línea 26: G armades e exarciadas. Línea 27: M complimiente; G docientos. Línea 28: G novecientas; M 900. Línea 30: G sian de vuestros. Línea 31: M entegrament; G y M doblas. Línea 33: G fayamos. Línea 34: G necesidad. Línea 38: G ditos Reyes de A. y de S. Línea 44: G dampnifiquen. Línea 45: G y M falta de la senyoria. Línea 51: G crebantamiento; $\mathrm{M}$ vendudas; G partir e yo. Línea 53: B y M Ruxones; G Ruscones. Línea 57: G puestos. Línea 59: M de aquella. Línea 60: M s.esdeundra. Línea 61: B y G fusta de Rimos; M rimos; G presor; M arrobadas. Línea 63: G desliurados. Línea 64: M facto. Línea 65: G presio. Línea 67: G falta por quienquiera; M quisquiera. Línea 68: M salta desde el primer manera hasta el del final de la línea. Línea 76: M prouebido. Línea 77: M verdadera. Línea $78 \mathrm{M}$ salta desde súbditos hasta súbditos vuestros en línea 79. Línea 79: G o dalguna. Línea 81: G almogaveres o collorados. Línea 85: G collorados. Línea 86: M dipputados. Línea 87: G X anos; M cristianos. Línea 88; M facto e servado. Línea 91: G Vera; G preimentos. Línea 93: G la dita paz... Falta hasta En testimonio, al final de línea 96. Línea 96: M cuentra venremos. Línea 97: M facta; G carta...; G magestat... E no sesmenos. Línea 100: G xrianisco; M cristianisco; G Barcelona. Línea 101: G cinquo... Falta el resto hasta Signo al principio de la línea 103. Línea 104: M Corsega. Líneas 103-105: G abrevia todo el párrafo como: Sig+no de don Martin... Rey daragon... Líneas 106-109: G abrevia todo el párrafo como: Sig+no de don Martin rey de Sicilia... Su transcripción del documento termina aquí. Línea 111: M e de don. Línea 119, como bien señala M, las últimas líneas corregidas no fueron las 60 y 66 sino las 80 y la 86 . 


\section{FUENTES DE ARCHIVO}

ACA, Pergaminos, Martín I, carpeta 326, n. 292.

ACA, C, Reg. 2315, f. 89r-92v.

\section{BIBLIOGRAFÍA}

ALARCÓN, M., GARCÍA DE LINARES, R. (1940): Los documentos árabes diplomáticos del Archivo de la Corona de Aragón, Madrid-Granada, CSIC.

BOFARULL, P. (1847): Colección de Documentos Inéditos del Archivo General de la Corona de Aragón, Tomo 1 [CODOIN, 1], Barcelona, Monfort, Doc. II, 25-34.

GIMÉNEZ SOLER, A. (1908): La corona de Aragón y Granada. Historia de las relaciones entre ambos reinos, Barcelona, Imprenta de la Casa Provincial de Caridad, 325-329 texto árabe; 330-333 texto romance. Antes en: "La Corona de Aragón y Granada", Boletín de la Real Academia de Buenas Letras de Barcelona, 4, 1907 1908, 353-361.

HINOJOSA, J. (1978): “Las relaciones entre los reinos de Valencia y Granada durante la primera mitad del siglo XV", Estudios de Historia de Valencia, Universidad de Valencia, 91-160, (Cf. 93-96).

LÓPEZ DE COCA, J. E. (2001-2002): “Sobre la emigración mudéjar al reino de Granada", Los mudéjares valencianos y peninsulares. Revista d'Història medieval, 12 , 241-258.

LÓPEZ PÉREZ, M. D. (1995): La Corona de Aragón y el Magreb en el siglo XIV (1331-1410). Barcelona, CSIC, 190-194.

MASALA, M. (1993): "Martino l'umano: trattato di pace con Granada (1405)" en: D'Arienzo, L. (Ed.), Sardegna, Mediterraneo ed atlantico tra medioevo ed età moderna. Studi storici in memoria di Alberto Boscolo. Volume secondo. Il Mediterraneo, Roma, Bulzoni, 315-343. Texto aragonés 327-331; texto árabe 332-336; traducción italiana de la parte árabe 337-341. 